\title{
Infarction of the optic nerve head in children with accelerated hypertension
}

\author{
DAVID TAYLOR, JAMES RAMSAY, SUSAN DAY, AND \\ MICHAEL DILLON \\ From the Hospital for Sick Children, Great Ormond Street, London WCI
}

SUMMARY Four cases of anterior ischaemic optic neuropathy occurred in children with accelerated hypertension. The cause may have been a sudden relative fall in arterial pressure which reduced the perfusion of the optic disc, whose circulation was compromised by long-standing hypertensive vascular disease.

The term anterior ischaemic optic neuropathy (AION) introduced by Hayreh ${ }^{1}$ emphasises that ischaemic optic neuropathy is essentially a condition affecting the optic nerve head. In extensive studies on the blood supply to this region Hayreh and others ${ }^{2-4}$ have shown that the prelaminar portion of the optic nerve head and the peripapillary choroid are supplied on an approximately segmental basis from the posterior ciliary arteries. The intraocular distribution of these arteries, and particularly that to the optic nerve head and peripapillary choroid, is much more susceptible to obliteration through a fall in perfusion pressure than is the central retinal artery. ${ }^{56}$

AION is predominantly a disease of the elderly, ${ }^{7}$ and this is thought to reflect at least in part an inability to adjust to changes in perfusion pressure due to pre-existing vascular disease. ${ }^{8}{ }^{9}$ Very few cases of AION have been reported in persons before late middle age. Pitcher and Curry ${ }^{10}$ recently reported 2 cases of presumed ischaemic optic neuropathy in women of 30 and 32 years receiving treatment for malignant hypertension, and some details of 3 of our cases were recently published. ${ }^{11}$ This paper reports the occurrence of AION in 4 children with accelerated hypertension.

\section{Case reports}

CASE 1

An 11-year-old boy, was admitted to the Hospital for Sick Children, Great Ormond Street, in June 1977. In September 1976 he was first examined by

Correspondence to David Taylor, FRCS, Eye Department, Hospital for Sick Children, Great Ormond Street, London WC1. his general practitioner for headaches and lassitude. There was a family history of migraine, and this was considered as a possible cause of the headaches. Four months later his optician saw him for 'irritated eyes' but found no abnormalities. By May 1977 he complained of seeing 'ants' on the wall, and after this there was an indefinite history of periods of dimmed vision. In June a blood pressure of $280 / 190$ $\mathrm{mmHg}$ was noted on an outpatient visit for headaches. He was admitted immediately to the local hospital, given diazoxide, $75 \mathrm{mg}(3 \mathrm{mg} / \mathrm{kg})$ intravenously, and transferred to Great Ormond Street. Blood pressure was $220 / 180 \mathrm{mmHg}$. Fundus examination showed swollen optic discs, haemorrhages, exudates, and increased vessel tortuosity. There were no visual symptoms, and neurological examination was normal.

Diazoxide $125 \mathrm{mg}(5 \mathrm{mg} / \mathrm{kg})$ intravenously, hydrallazine $10 \mathrm{mg}(0.4 \mathrm{mg} / \mathrm{kg})$ intramuscularly, and diazepam $5 \mathrm{mg} / \mathrm{kg}$ intravenously were given, with rapid reduction of blood pressure to $130 / 80$ $\mathrm{mmHg}$, and he was given propranolol $25 \mathrm{mg} 3$ times daily and hydrallazine $20 \mathrm{mg}(2.5 \mathrm{mg} / \mathrm{kg})$ orally. Later that evening the blood pressure again rose to $160 / 110 \mathrm{mmHg}$, and an additional dose of diazoxide $125 \mathrm{mg}$ was given intravenously. Frusemide $20 \mathrm{mg} 3$ times a day was added. Two hours later the blood pressure had fallen to $120 / 90 \mathrm{mmHg}$. He complained of a sudden decrease in vision, and he was unable to count fingers. Throughout the night the patient remained relatively hypotensive (as low as $90 / 50 \mathrm{mmHg}$ ) and became comatose. Medications were stopped and saline volume replacement was instituted. The blood pressure was restored to $150 / 90 \mathrm{mmHg}$, and when he regained consciousness he had no perception of light and the pupils were unreactive. The optic nerves showed pallid 
swelling, and retinal and choroidal infarcts were noted (Fig. 1). The electroretinogram was normal, but the flash visually evoked cortical responses showed only a doubtful cortical response in keeping with gross, though possibly not complete, loss of function of visual pathways and/or cortex.

Further investigations revealed bilateral renal scarring associated with vesicoureteric reflux, and bilateral ureteric reimplantation was performed in September 1977. The blood pressure has since been well controlled on propranolol, prazosin, and frusemide. In May 1979 he still had no perception of light, and gross optic atrophy was present (Fig. 2). On 14 May 1980 he hit his head during a bout of fisticuffs at the blind children's school that he attended and said that he could see immediately afterwards. On examination the next day he could definitely perceive light in both eyes and had a perception of hand movements in the left eye. Both pupils reacted to light.

CASE 2

A 12-year-old girl was admitted to Great Ormond Street in May 1978 with a history that 10 weeks before admission a right facial palsy associated with earache had occurred, which was attributed to an infection. Severe frontal headaches developed 5 weeks later but were unexplained. One week before admission she noticed a 'yellow wire' in front of her left eye, with associated poor vision. A similar event happened to her right eye on the day of admission. Before this there was a history of urinary

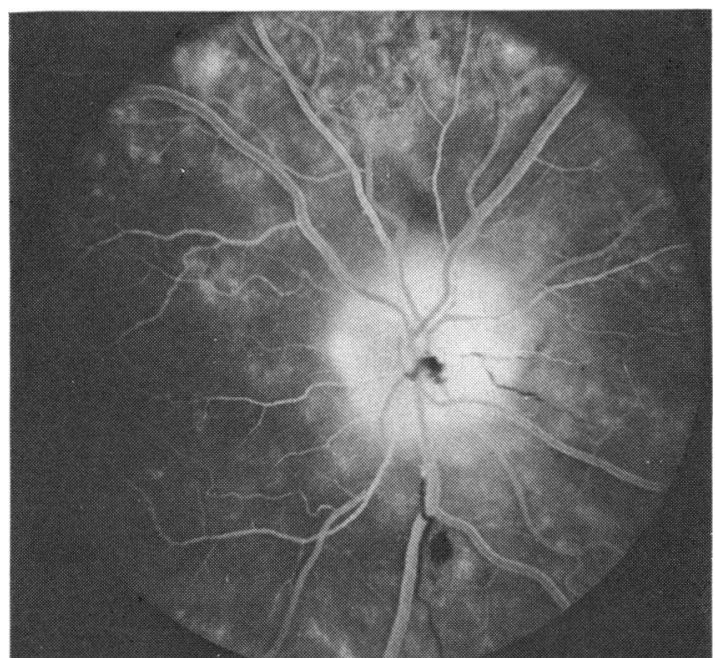

Fig. 1 Case 1. Fluorescein angiogram of the left eye on 11 July 1977 showing a haemorrhage on the optic disc, leakage of dye at the disc, and occluded retinal arterioles. There were marked choroidal filling defects.

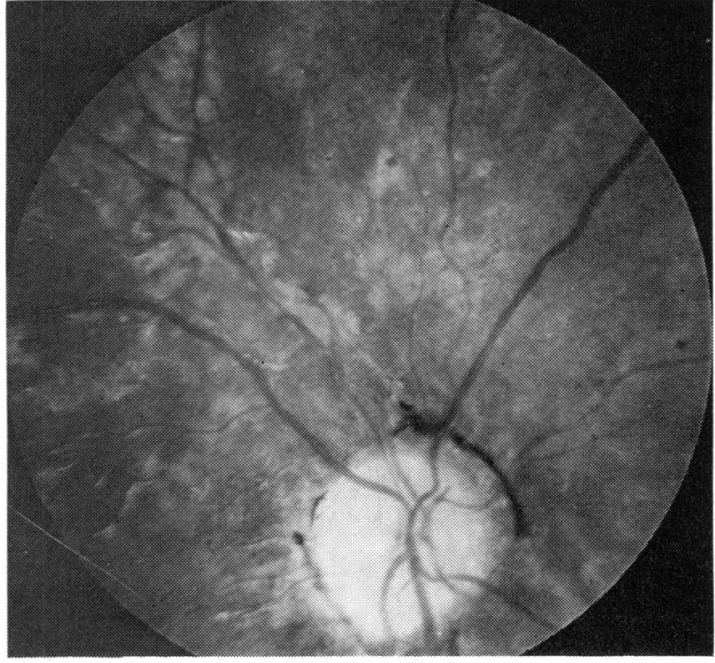

Fig. 2 Case 1. The right fundus in May 1979. The eye is blind and the optic disc is pale, without small vessels. There is gross loss of nerve fibres and evidence on funduscopy of extensive choroidal infarction with overlying pigment epithelial defects. There is pigment accumulation at the margin of the disc superonasally. The changes were bilateral and symmetrical.

tract infection as an infant, but an intravenous pyelogram had been normal at 18 months of age. The paternal grandfather had been hypertensive.

On admission to the hospital that referred her to Great Ormond Street the blood pressure was 270/180 $\mathrm{mmHg}$, and vision was reduced to counting fingers in the right eye and hand movements in the left eye. Bilateral optic disc swelling was present (Fig. 3). Diazoxide $150 \mathrm{mg}(4 \mathrm{mg} / \mathrm{kg}$ ) was given intravenously as well as methyldopa $500 \mathrm{mg}(14 \mathrm{mg} / \mathrm{kg})$ orally and Navidrex $K$ (cyclopenthiazide and potassium chloride) $0.5 \mathrm{mg}(0.01 \mathrm{mg} / \mathrm{kg})$. Blood pressure rapidly fell to $140 / 110 \mathrm{mmHg}$ and she was admitted to the Hospital for Sick Children, Great Ormond Street. Four hours later she had no perception of light and was restless. During the next 12 hours the blood pressure had further decreased to $90 / 60 \mathrm{mmHg}$. She developed a flaccid paraplegia. Saline infusion was given, but anuria ensued and peritoneal dialysis was required. Over the following weeks blood pressure stabilised, and a gradual motor improvement oscurred, though vision remained poor, with no perception of light in the right eye and hand movement perception in the left eye (Fig. 4). One month later she could count fingers with the left eye only, and she was able to walk with crutches.

Reflux nephropathy was diagnosed, and she underwent bilateral ureteric reimplantation 3 months after her first admission. When last seen in February 


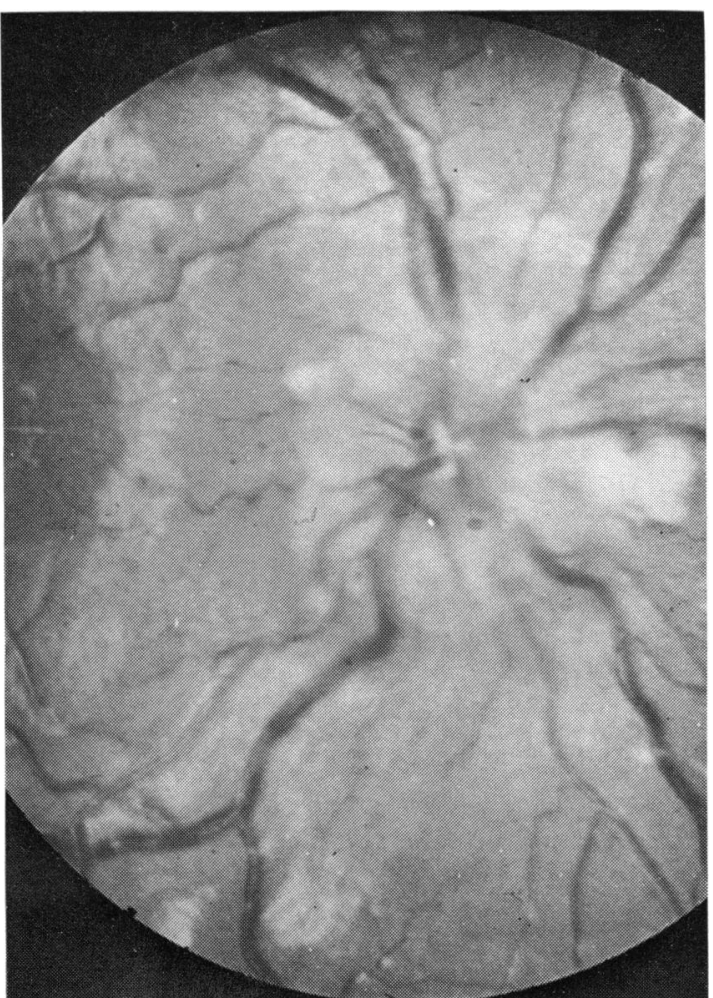

Fig. 3 Case 2. The right fundus on admission showing optic disc swelling with nerve fibre infarcts (cotton-wool spots) and venous dilatation. The changes were bilateral and symmetrical.

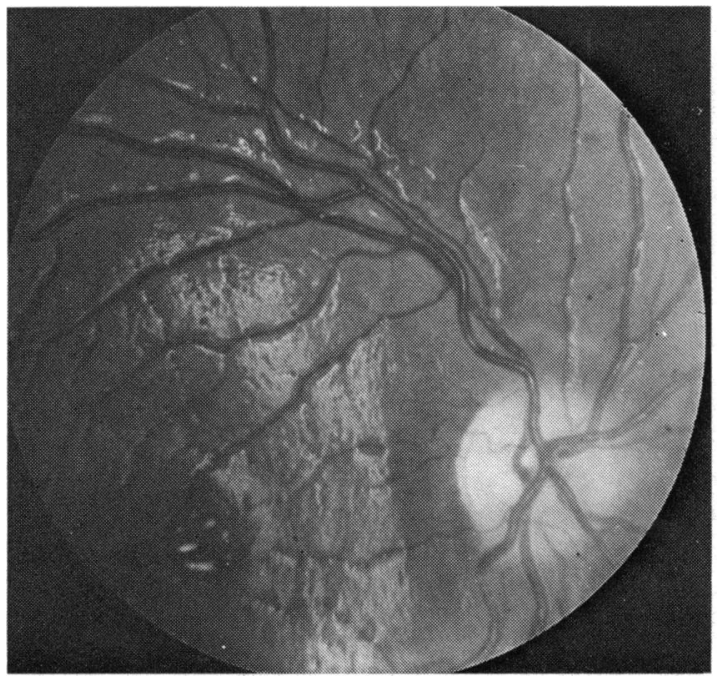

Fig. 4 Case 2. The right fundus showing a gross loss of nerve fibres causing undue prominence of the retinal vessels, the remains of a macular star, and a pale, slightly swollen disc.
1979 she had no perception of light in the right eye and an acuity of 2/60 in the left eye. Blood pressure was satisfactorily controlled with propranolol and prazosin. Fluorescein angiography (Fig. 5) performed at this time showed underperfused optic discs but normal retinal vessels and pigment epithelium. An electroretinogram (ERG) was normal, but no definite visually evoked cortical responses (VER) were present.

\section{CASE 3}

An 11-year-old boy was admitted to Great Ormond Street in November 1976 after a 4-year history of unexplained headaches, vomiting, polyuria, and polydipsia. For 2 months before admission he had bouts of severe abdominal pain. He was initially admitted to his local hospital after transient loss of vision while straining at stool. His blood pressure at that time was $190 / 110 \mathrm{mmHg}$. He was anaemic, with a haemoglobin of $6.6 \mathrm{~g} / \mathrm{dl}$, and gross melaena was present. He was given diazoxide $120 \mathrm{mg}(3 \mathrm{mg} /$ $\mathrm{kg})$, hydrallazine $15 \mathrm{mg}(0.26 \mathrm{mg} / \mathrm{kg})$ intravenously, and 2 units of blood, He was then transferred to Great Ormond Street. Although conscious, he was confused and his blood pressure was $160 / 80 \mathrm{mmHg}$. Visual acuity was counting fingers at 2 metres in each eye. There was bilateral gross pallid optic disc swelling (Fig. 6), with haemorrhages, exudates, and bilateral macular stars, and with cotton-wool spots adjacent to the discs.

Propranolol $40 \mathrm{mg} 3$ times daily $(3.5 \mathrm{mg} / \mathrm{kg} /$ day), and hydrallazine $25 \mathrm{mg} 3$ times daily ( $2 \mathrm{mg} / \mathrm{kg} /$ day)

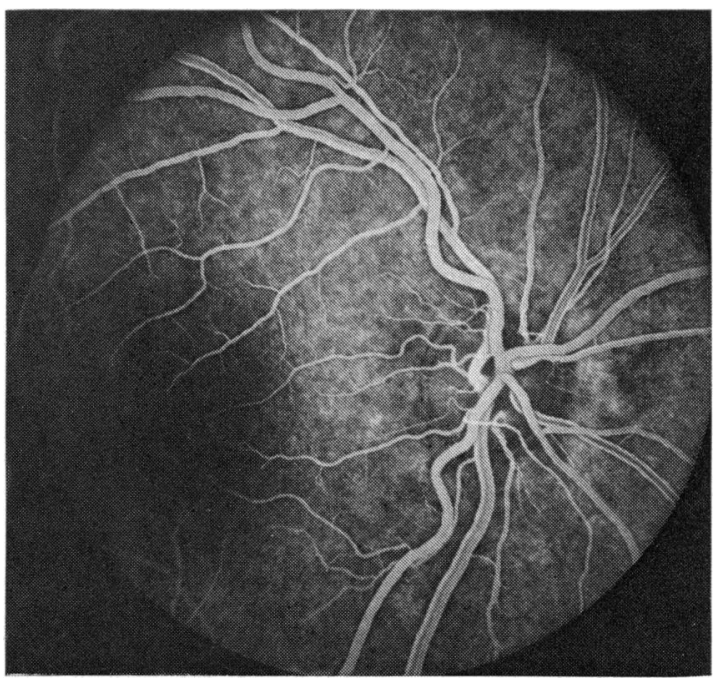

Fig. 5 Case 2. Fluorescein angiogram in February 1979 showing avascularity of the optic disc but normal retinal vessels and choroidal filling. 
Fig. 6 Case 3. Left fundus on admission showing gross optic disc swelling with infarcts, a few haemorrhages and a macular star.

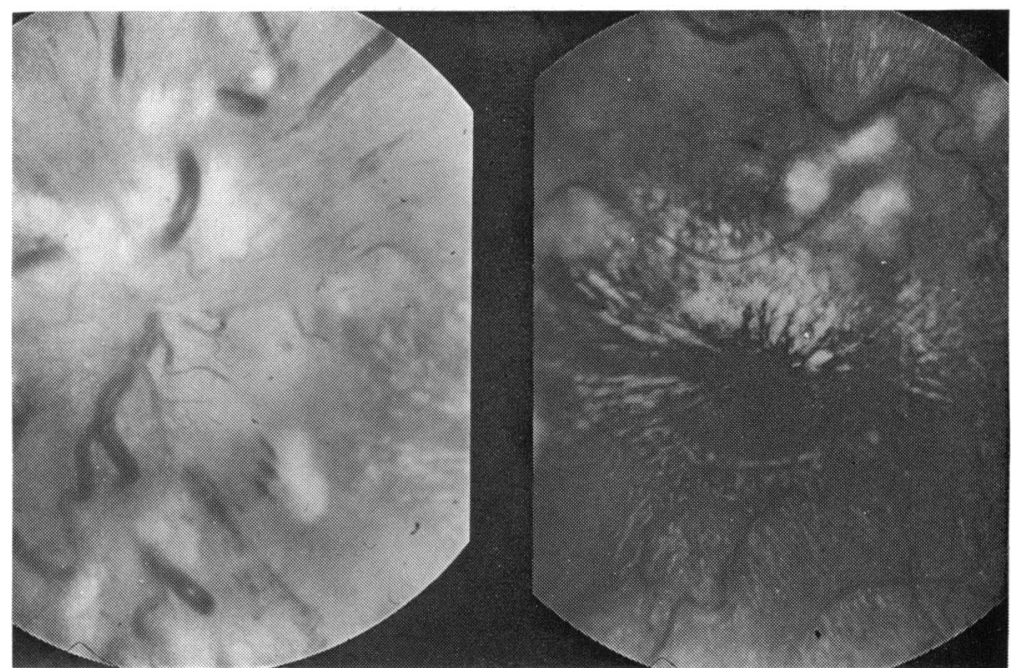

were given orally. Vision decreased in the left eye to no perception of light the day after admission. Intravenous dexamethasone was administered, and a left stellate ganglion block was performed. The vision improved to finger counting in the left eye and $4 / 24$ in the right eye, and the pupil reactions became more brisk. Fluorescein angiography (Figs. 7 and 8) showed areas of capillary closure round the optic disc and areas of grossly dilated capillaries which leaked. An ERG showed a well-defined, moderate-amplitude negative component followed

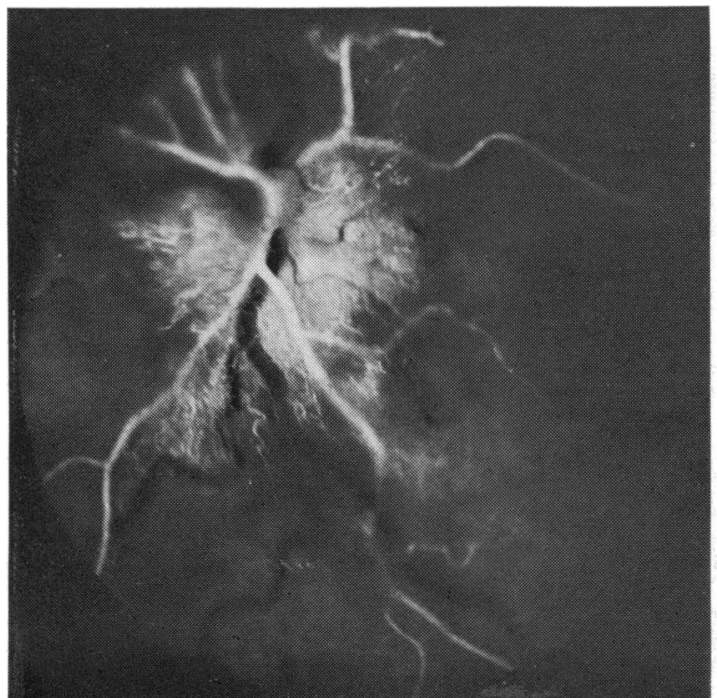

Fig. 7 Case 3. Left fluorescein angiogram, early arterial phase, on admission showing capillary dilatation, patchy optic disc filling, and arteriolar irregularity. by a less clearly defined positive component occurring over the first 50 milliseconds following the stimulus. The VER showed no midoccipital response until $100 \mathrm{~ms}$, when an ill-defined, low-amplitude positive charge began, reaching a peak at around $150 \mathrm{~ms}$. The response was better with right than left eye stimulation.

Twelve days after admission he had an intracerebral haemorrhage in the left parieto-occipital region demonstrated by a CT scan. The blood pressure remained labile, and minoxidil $2.5 \mathrm{mg} 3$

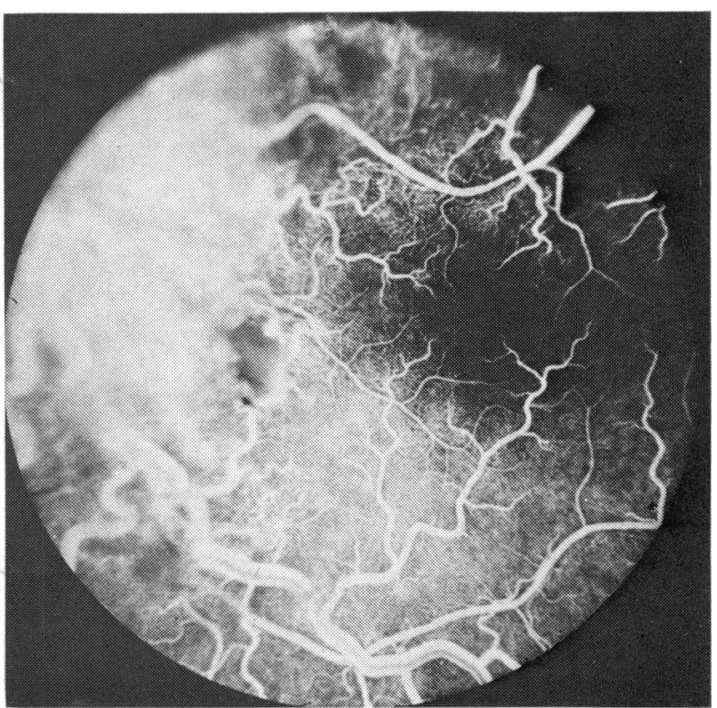

Fig. 8 Case 3. Left fluorescein angiogram, arteriovenous phase showing optic disc leakage and capillary dilatation. There is an infarct between the macula and disc with a tiny haemorrhage inferior to it. 


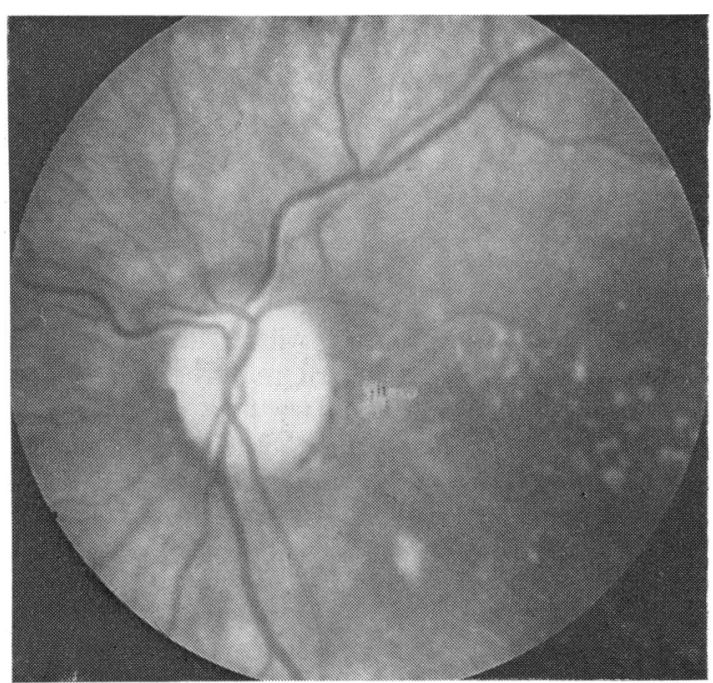

Fig. 9 Case 3. The left fundus in March 1979. The optic disc is pale and avascular and there are the remains of the macular star seen in Fig. 6. Choroidal infarcts were also noted. The acuity was 3/60 in the left eye and 2/60 in the right eye.

times daily $(0.5 \mathrm{mg} / \mathrm{kg} /$ day $)$ and frusemide $30 \mathrm{mg}$ 4 times daily $(2.5 \mathrm{mg} / \mathrm{kg} /$ day $)$ were added.

An intravenous pyelogram showed a small scarred left kidney, and the plasma renin was elevated. A left nephrectomy was performed. Antihypertensive therapy was gradually reduced after the operation.

In September 1979 the vision was reassessed. Acuity was $1 / 60$ in the right eye and $5 / 60$ in the left eye. A dense right homonymous haemianopia was present. Both nerves were pale, and evidence of previous choroidal infarcts was present. Pigmentary mottling was present at the fovea.

\section{CASE 4}

A $9 \frac{1}{2}$-year-old English boy living in the Middle East was admitted to Great Ormond Street in April 1979 after a 3-month history of increasingly severe headaches. One brother had died when 23 years old of Goodpasture's syndrome. In mid April a generalised convulsion prompted admission to the local hospital in Dubai, where the patient was comatose with a blood pressure of $260 / 190 \mathrm{mmHg}$. Haematuria was present. He was treated with diazepam and hydroxyzine and transferred to Great Ormond Street. On admission he was semiconscious and had a blood pressure of $190 / 100 \mathrm{mmHg}$ rising to $230 / 100$. The pupils were unequal and sluggishly reacting to light, there was bilateral disc swelling with haemorrhages, and a right facial weakness and hemiparesis. CT scan revealed diffuse cerebral oedema.
He was initially given diazoxide intravenously; $50 \mathrm{mg}$ produced no response, so a further $110 \mathrm{mg}$ was administered, with a reduction of blood pressure to $140 / 95 \mathrm{mmHg}$. Minoxidil $2.5 \mathrm{mg}(0.1 \mathrm{mg} / \mathrm{kg})$ twice daily and propranolol $20 \mathrm{mg}(1.25 \mathrm{mg} / \mathrm{kg})$ 3 times daily orally were started. Although stuporose he became rousable and claimed he could see, identifying the doctor's neck tie. At this stage his pupils were briskly reactive. Two and a half hours after the second injection of diazoxide the right pupil became larger than the left, though they still both reacted to light, but there was real doubt whether he could see. A few hours later his blood pressure dropped momentarily to $100 / 60 \mathrm{mmHg}$, and at this time he was restless and less reponsive and the pupils became unreactive, then sluggish, with a right relative afferent pupillary defect. Intravenous saline was begun, dexamethasone was administered, and the blood pressure rose to $150 / 90$ $\mathrm{mmHg}$. A left stellate ganglion block was performed and repeated twice, 8 hours and 20 hours later. Minoxidil and propranolol were temporarily discontinued. Two days after admission both pupil reactions were again present, but the patient said he could not see. The blood pressure stabilised on oral therapy at $145 / 105 \mathrm{mmHg}$. Over the following 24 hours vision rapidly improved to $3 / 24$ right eye and 3/36 left eye. Both pupils reacted sluggishly, and a left relative afferent defect was present. The patient also had a left total homonymous hemianopia. One week later vision had improved to 6/9 right eye and $6 / 12$ left eye. Moderate disc oedema remained, but pallor was noted as well. Ten days later (approximately 3 weeks after admission) acuity had improved in $6 / 6$ in each eye, though a dense left homonymous hemianopia remained.

He then suffered a sudden 'collapse', with dysconjugate gaze believed to represent either a brain stem haemorrhage or an ictal episode. The blood pressure at this time was $140 / 80 \mathrm{mmHg}$. A CT scan was normal. These symptoms rapidly resolved.

In mid April 1979, although the ERG was normal, the VER showed a definite cortical response, of increased latency and somewhat ill defined. In May 1979 the VER was similar but less pronounced over the right hemisphere.

An intravenous pyelogram revealed bilateral renal scarring associated with massive vesicoureteric reflux.

Four months after admission his blood pressure was controlled on propranolol, hydrallazine, and frusemide. Vision remained $6 / 6$ in each eye. Pupils reacted to light and accomodation in the left eye somewhat more briskly than the right. The cause of this relative efferent defect has not been ascertained. A dense left homonymous hemianopia was present. Both optic nerves were pale. 


\section{Discussion}

The clinical and fluorescein angiographic evidence suggests that these children developed AION. All the cases had 2 features in common: firstly, longstanding severe hypertension with disc swelling, and secondly a sudden relative fall in systemic blood pressure, although to levels that would not be considered hypotensive in normal children.

Permanent visual loss in otherwise healthy children following a sudden hypotensive episode of any cause must be a rare event, if ever recorded, and it seems likely that some regulatory mechanism exists in health allowing the optic nerve head to adjust to a fall in perfusion pressure. The apparent failure of the optic nerve head to adjust in malignant hypertension might be interpreted in 2 ways. Firstly, the presence of disc swelling or a microvasculopathy affecting the vessels supplying the optic nerve head could make the optic disc perfusion tenuous and therefore vulnerable to a fall in systemic blood pressure. Secondly, the flexibility of the regulatory mechanism might be adversely affected.

The optic disc swelling in hypertension can be accounted for by 2 mechanisms. The disc swelling associated with malignant hypertension shares with that found in other conditions the prominent feature of axonal swelling. ${ }^{12-15}$ Various studies ${ }^{16-18}$ have suggested that this swelling results from an axoplasmic flow stasis at the optic nerve head. The cause of the stasis is thought to depend on the aetiology of the disc swelling.

From a histopathological study of optic disc and retinal changes Ashton ${ }^{19}$ concluded that the optic disc features of malignant hypertension were, in part, the result of ischaemia consequent on microvascular changes similar to those occurring in the retina. That stasis of axoplasmic flow can occur in ischaemia has been demonstrated in the experimental work of Levy and Adams. ${ }^{20}$

The adverse effect on perfusion of disc swelling itself in adults is shown in the increased risk of AION where there is pre-existing papilloedema secondary to raised cerebrospinal fluid pressure, and this has been interpreted in terms of an increase in tissue pressure causing an imbalance in the Starling equilibrium as it applies to the perfusion of the optic nerve head.

Raised CSF pressure secondary to intracranial space-occupying lesions in children is common, and yet visual loss attributable to AION is certainly extremely rare, if it occurs, even in children undergoing neurosurgery, some of whom will have been given profound hypotensive anaesthesia. This suggests that swelling of the optic nerve head does not itself significantly affect disc perfusion in chil- dren, even in the presence of a very low perfusion pressure.

Little study has been made of regulatory mechanisms controlling perfusion of the optic nerve head. However, experimental studies on the effect of changes in systemic blood pressure on the microvasculature of the cerebral circulation ${ }^{21}$ and on the retinal circulation ${ }^{22}{ }^{23}$ suggest that a form of autoregulation occurs in which a rise or fall in the systemic blood pressure is associated with a decrease or an increase respectively in the calibre of the precapillary arterioles, so that the capillary flow remains relatively constant. The very high systemic blood pressure of malignant hypertension causes a 'forced vasodilatation' of the precapillary arterioles and an increase in blood flow in the capillaries. ${ }^{24}$ This may result in the development of oedema, which in the brain is thought to give rise to some of the features of hypertensive encephalopathy.

Studies on autoregulation in the cerebral circulation by Strandgaard ${ }^{21}$ suggest that in hypertension the upper and lower limits of systemic blood pressure between which autoregulation occurs are reset at a higher level. Subsequent lowering of the blood pressure induces a return of the range of autoregulation to normal. In long-standing hypertension this readjustment to normal may be very slow, and this is interpreted as reflecting the development of secondary changes in the microvasculature. Thus in long-standing malignant hypertension a sudden lowering of the systemic blood pressure even to levels above the normal may bring it below the lower limit of autoregulation, in which case cerebral perfusion will fail.

It seems probable that such a failure of autoregulation was the cause of the transient and permanent neurological defects reported in elderly hypertensives following reduction of the blood pressure to a normal level. ${ }^{25}$

In view of the comparable responses of the cere. bral and retinal circulations to changes in systemic blood pressure it would seem logical that the circulation of the optic nerve head shares similar characteristics in health and disease. We feel that the AION occurring in the cases described reflects a failure of autoregulation at the optic nerve head, the high systemic blood pressure causing the range of autoregulation to be reset to a higher level and the long-standing nature of the condition causing secondary changes in the microvasculature such that the rapid lowering of the systemic blood pressure was not matched by calibre changes in the precapillary arterioles. Thus perfusion of the optic nerve head failed. The extent to which this was superimposed on a general climate of ischaemia at the optic nerve head brought about by the severe 
microvasculopathy is uncertain. The adverse effect on perfusion of the disc swelling itself is not thought to be significant in these cases.

In 2 of our patients there was some visual loss preceding the therapeutic reduction in blood pressure; one patient (case 3) had a gastrointestinal haemorrhage but the other (case 2) had no obvious cause for a hypotensive episode. This is difficult to explain unless either she had an episode of undetected hypotension or her optic nerve was more severely affected by the hypertension, though there was no clinical indication of this.

Cases 2, 3, and 4 had a combination of ischaemic optic neuropathy and cerebral or spinal cord damage, showing how similarly all areas of the central nervous system are affected by hypertension.

It has become common practice among paediatricians in the management of malignant hypertension to attempt to reduce the blood pressure as rapidly as possible so as to bring it within the range of autoregulation, thereby reducing the risk of neurological complications. ${ }^{26}$ The development of powerful hypotensive agents has brought the aim of rapid reduction of blood pressure in malignant hypertension within reach. It seems that the benefits of such a rapid reduction of blood pressure to normal have been bought at the price of compromising the cerebral blood flow through reducing the blood pressure below the lower limit of autoregulation. As indicated by Strandgaard, ${ }^{26}$ the microvascular changes that accompany long standing malignant hypertension tend to slow down the rate at which the range of autoregulation readjusts to normal.

The implications for management are twofold. Firstly, in the early phase of treatment the blood pressure should be lowered only to the extent that keeps it at a level that is probably above the lower limit of autoregulation. Secondly, further reduction of the blood pressure to a normal level should not be at a greater rate than the rate of downward adjustment of the range of autoregulation towards normal. These are not rules as to management, but a guideline may be towards an initial reduction by $30 \%$ followed by a gradual return to normal over 24 to 72 hours. These considerations would seem to apply equally to the cerebral and the optic nerve head circulations.

Theoretical considerations suggest that other protective measures may be appropriate. The relationship between AION and intraocular pressure, now well established, ${ }^{27}$ suggests that the perfusion of the optic nerve head might be improved by lowering the intraocular pressure. Unfortunately carbonic anhydrase inhibitors and osmotic agents might be contraindicated in renal disease. Locally acting ocular hypotensive agents such as pilocarpine and timolol have only a very limited effect in lowering the intraocular pressure below normal. More effective in this context is ocular massage, but this would need to be repeated very frequently and might prove difficult in an ill child.

In the hypertensive baboon cervical sympathectomy may reduce the lower limit of blood pressure at which autoregulation occurs. Hence cases 3 and 4 had cervical sympathetic blocks. This may have been partially successful in case 3 , since the acuity of the treated eye has remained less severely affected. However, the effectiveness of this procedure must be limited in the presence of severe microvasculopathy.

\section{References}

1 Hayreh SS. Anterior Ischaemic Optic Neuropathy. Berlin: Springer, 1975: 1.

2 Hayreh SS. Pathogenesis of visual field defects. $\mathrm{Br} J$ Ophthalmol 1970; 54: 289-311.

3 Anderson DR. Vascular supply to the optic nerve of primates. Am J Ophthalmol 1970; 70: 341-51.

4 Henkind P, Levitsky M. Angioarchitecture of the optic nerve. 1. The Papilla. Am J Ophthalmol 1979; 68: 979-86.

5 Hayreh SS, Revie IHS, Edwards J. Vasogenic origin of visual field defects and optic nerve changes in glaucoma. Br J Ophthalmol 1970; 54: 461-72.

6 Hayreh SS. Optic disc changes in glaucoma. Br J Ophthalmol 1972; 58: 175-85.

7 Eagling EM, Sanders MD, Miller SJH. Ischaemic papillopathy. Br J Ophthalmol 1974; 58: 990-1008.

8 Heyreh SS. Anterior Ischaemic Optic Neuropathy. Berlin: Springer, 1975: 15-6.

9 Hayreh SS, Baines JAB. Occlusion of the posterior ciliary artery. 1. Effects on choroidal circulation. $B r J$ Ophthalmol 1972; 56: 719-35.

10 Cove DH, Seddon M, Fletcher RF, Dukes DC. Blindness after treatment for malignant hypertension. $\mathrm{Br}$ Med $\mathrm{J}$ 1979; ii: 245-6.

11 Hulse JA, Taylor DSI, Dillon MJ. Blindness and paraplegia in severe childhood hypertension. Lancet 1979; i: 553-6.

12 Garner A, Ashton N, Tripathi R, Kohner EM, Bulpitt CJ, Dollery CT. Pathogenesis of hypotensive retinopathy. Br J Ophthalmol 1975; 59: 3-44.

13 Tso MOM, Fine BS. Electron microscopy study of papillodema in man. Am J Ophthalmol 1976; 82: 424-34.

14 Minckler DS, Tso MOM. Experimental papillodema produced by cyclocryotherapy. Am J Ophthalmol 1976; 82: 577-89.

15 Hayreh SS. Optic disc oedema in raised intracranial pressure. V. Pathogenesis. Arch Ophthalmol 1977; 95: 1553-65.

17 Minckler DS, Tso MOM, Zimmerman LE. A light microscope, autoradiographic study of axoplasmic transport in the optic nerve head during ocular hypotomy, increased intraocular pressure and papillodema. $A m J$ Ophthalmol 1976; 82: 741-57.

18 Tso MOM, Hayreh SS. Optic disc oedema in raised intracranial pressure. IV. Axoplasmic transport in experimental papillodema. Arch Ophthalmol 1977; 95: 1458-62.

19 Ashton N. The eye in malignant hypertension. Trans Am Acad Ophthalmol Otolaryngol 1972; 76: 17-40.

20 Levy NS, Adams CK. Slow axonal protein transport and 
visual function following retinal and optic nerve ischaemia. Invest Ophthalmol Visual Sci 1975; 14: 91-7.

21 Strandgaard S. Autoregulation of cerebral circulation in hypertension. Acta Neurol Scand 1978; 57 (suppl 66): 1-82.

22 Hodge JV, Dollery CT. Retinal soft exudates. A clinical study by colour and fluorescein photography. QJ Med 1964; 33: 117-31.

23 Russell RWR. Fvidence for autoregulation in human retinal circulation. Lancet 1973 ; ii: 1048-50.
24 Johansson B, Strandgaard S, Lassen NA. On the pathogenesis of hypertensive encephalopathy. Circ Res 1974; 34: 167-71 (suppl).

25 Jackson G, Pierscianowski TA, Mahon W, Condon J. Inappropriate antihypertensive therapy in the elderly. Lancet 1976; ii: 1317-8.

26 Lloyd-Still JD, Cottom DG. Severe hypertension in childhood. Arch Dis Child 1967; 42: 34-9.

27 Hayreh SS. Anterior Ischaemic Optic Neuropathy. Berlin: Springer, 1975: 123. 